\title{
EL REGIONALISMO POSTLIBERAL EN SUDAMÉRICA: ¿EN FASE DE DESPOLITIZACIÓN? LOS CASOS DE ALBA, UNASUR Y MERCOSUR
}

\author{
POST-LIBERAL REGIONALISM IN SOUTH AMERICA: IN A \\ DEPOLITICIZATION PHASE? THE CASES OF ALBA, \\ UNASUR AND MERCOSUR
}

\author{
María Victoria Alvarez ${ }^{1}$ \\ ORCID: 0000-0002-2203-5082
}

\section{RESUMEN}

Luego de cinco décadas de olas de auge y decadencia, el regionalismo en Sudamérica, en los primeros años del siglo XXI, fue repensado en un diseño postliberal: en particular, una iniciativa tanto de complementación como de cooperación materializada en el ALBA, al igual que un esquema de diálogo intersectorial y cooperación política, la UNASUR. Por su parte, el MERCOSUR, un sistema resiliente de la anterior ola de regionalismo sudamericano, también se renovó en clave postliberal.

Una década después del surgimiento del regionalismo postliberal, se asiste a una fase de pérdida de dinamismo. En este trabajo, describimos los últimos desarrollos en torno a ALBA y UNASUR, así como el MERCOSUR, siguiendo la perspectiva de Dabène de ciclos de politización. El interrogante es si estos esquemas se encuentran en una fase de despolitización. Si esto es así, nos preguntamos si serán lo suficientemente resilientes como para superar dicha fase y transitar hacia una de repolitización.

Palabras clave: Sudamérica; regionalismo postliberal; ciclos de politización; ALBA; UNASUR; MERCOSUR.

\section{ABSTRACT}

After five decades of waves of boom and decline of regionalism, in the early years of the 21st century, South American regionalism was reconsidered in a post-liberal design: in particular, an initiative of complementarity and cooperation materialized in ALBA, as well as a scheme of cross-sectoral dialogue and political cooperation, UNASUR. Meanwhile, MERCOSUR, a resilient regionalist system, was also renovated in post-liberal terms. A decade after the rise of post-liberal regionalism, we attend to a phase of less dynamism. In this paper we describe the latest developments of ALBA and UNASUR, as well as MERCOSUR, following the perspective of Dabène of cycles of politicization. The question is whether these schemes are in a phase of depoliticization. If this is so, this development raises the question of whether they will be the sufficiently resilient as to overcome this phase and move toward one of deeply repoliticization.

Keywords: South America; post-liberal regionalism; cycles of politicization; ALBA; UNASUR; MERCOSUR.

1 Universidad Nacional de Rosario, Facultad de Ciencia Política y Relaciones Internacionales. Doctora en Relaciones Internacionales. Rosario, Argentina. Profesora en la Facultad de Ciencia Política y Relaciones Internacionales. Correo electrónico: maria.alvarez@fcpolit.unr.edu.ar 


\section{Introducción}

Luego de cinco décadas de subsecuentes olas de auge y decadencia del regionalismo en América Latina, en los primeros años del siglo XXI, sobre todo en Sudamérica, gobiernos de izquierda recuperaron el espacio político y pusieron en debate los intereses, la racionalidad y los objetivos de la integración regional, como se había aceptado hasta ese momento (Sanahuja, 2012, p. 26). Así, se dio el contexto propicio para el advenimiento de una nueva ola regionalista, caracterizada por la aparición de estructuras inéditas que se yuxtapusieron con esquemas preexistentes como el Mercado Común del Sur (MERCOSUR) y la Comunidad Andina (CAN).

El regionalismo fue repensado en un diseño postliberal (Da Motta y Ríos, 2007; Sanahuja , 2010, 2012), que también recibió otros calificativos como posthegemónico (Riggirozzi y Tussie, 2012)² y que intentaba ir más allá del regionalismo abierto de la década anterior: en particular, una iniciativa innovadora de complementación y de cooperación materializada en la Alianza Bolivariana para los Pueblos de Nuestra América (ALBA), más un esquema de diálogo intersectorial y cooperación política, la Unión de Naciones Suramericanas (UNASUR).

En el nivel regional, se configuró la Comunidad de Estados Latinoamericanos y Caribeños (CELAC) como un instrumento de diálogo político y cooperación en ámbitos como "el desarrollo social, la educación, el desarme nuclear, la agricultura familiar, la cultura, las finanzas, la energía y el medio ambiente”, entre otros (SELA, n. d.). La CELAC buscaba tener un alto perfil político, reflejando la herencia histórica del Grupo de Río (Sanahuja, 2012, p. 57), aunque en los últimos tiempos ha perdido vigor y relevancia. ${ }^{3}$

En este punto, se vuelve fundamental esclarecer las nociones de regionalismo e integración regional, dado que no constituyen conceptos intercambiables. Seguimos a Hurrell (1995), quien distingue entre cinco categorías de regionalismo: regionalización, identidad regional, conciencia regional, cooperación regional interestatal (en la cual se halla la integración regional) y cohesión regional. En particular, la noción de cooperación regional implica la negociación y construcción de acuerdos o regímenes interestatales o intergubernamentales, donde la estructura institucional puede ser formal, pero también laxa. Podría involucrar

2 Además de las ya mencionadas, surgieron otras categorizaciones para adjetivar al período posterior a la crisis del regionalismo abierto: regionalismo social y productivo (Briceño Ruiz, 2011), regionalismo postneoliberal (Bizzozero, 2011), regionalismo heterodoxo (Van Klaveren, 2012).

3 La CELAC constituye un mecanismo de cooperación y concertación política regional y no un esquema subregional; por lo tanto, no será abordada en este trabajo. 
la organización de reuniones regulares con algunas reglas de funcionamiento $\mathrm{y}$ el diseño de mecanismos tanto para la preparación como para el seguimiento de los acuerdos forjados (Hurrell, 1995, p. 42). ${ }^{4}$ La integración regional, por su parte, involucra decisiones de los gobiernos sobre políticas específicas, con el propósito de remover las barreras a la circulación de bienes, servicios, capitales y personas (Hurrell, 1995, p. 43).

La distinción entre esas dos categorías resulta vital a la hora de diferenciar esquemas subregionales como UNASUR y ALBA; por un lado, ninguno de los ellos "puede ser considerado una iniciativa de integración en el significado estándar de este término, ya sea por su contenido económico, político o legal" (Sanahuja, 2012, p. 31-32), y MERCOSUR o CAN, por otro.

Lo que se evidencia claramente en los últimos tiempos, en Sudamérica, es la proliferación y el solapamiento de esquemas de cooperación e integración. Lejos de ser una contradicción, creemos que "es necesario ajustar los lentes conceptuales a la realidad de la región y olvidar los modelos teleológicos de integración" (Soares de Lima, 2016, p. 79).

Pero más allá del debate en torno a la dicotomía divergencia-convergencia y al hecho de que los esquemas regionales latinoamericanos puedan entenderse como proyectos ideologizados que conducen a la fragmentación (Malamud y Gardini, 2012) o "como expresiones de una heterogeneidad que es propia de la región, y que no hay que ocultar bajo pretensiones de homogeneidad" (Vivares y Dolcetti-Marcolini, 2016, p. 31); la posibilidad de encontrarse frente a una fase de despolitización del regionalismo postliberal es una interpelación.

Una década después del surgimiento o de la renovación de esquemas regionales y subregionales de cooperación e integración en clave postliberal, éstos concurren en una fase de pérdida de dinamismo, en el mejor de los casos, o de desaparición, en el peor. Ello conduce a preguntarnos: ¿la etapa de regionalismo postliberal está agotada?, es decir, nos preguntamos si nos encontramos "frente a un 'fin de ciclo' en la región” (Racovschik y Raimundi, 2016, p. 17). Para poder responder a este interrogante, se utilizará la noción de ciclos de politización de Dabène, que puede explicar las irregularidades observadas en la mayoría de los procesos de integración y evita las interpretaciones teleológicas respecto del éxito o fracaso del regionalismo (Dabène, 2012, p. 42).

4 Estos acuerdos cooperativos sirven para responder a desafíos externos y coordinar posiciones regionales en instituciones o foros internacionales. También pueden servir para asegurar ganancias de bienestar, promover valores comunes o resolver problemas habituales, especialmente, los derivados de un creciente nivel de interdependencia (Hurrell, 1995, p. 42). 
El objetivo del trabajo es analizar si ALBA y UNASUR se encuentran en una fase de despolitización, teniendo en cuenta dos elementos que se derivan del esquema teórico-conceptual de Dabène: la concepción de intereses comunes y la construcción de arreglos institucionales. Eventualmente, si esto es así, se plantea la pregunta de si serán lo suficientemente resilientes como para superar dicha fase y transitar hacia una de repolitización. Del mismo modo, se aplica este marco para analizar el estado del MERCOSUR, que ha sufrido anteriores etapas de politización y despolitización. ${ }^{5}$

El trabajo se organiza de la siguiente manera: luego de esta introducción, se esbozan los lineamientos teórico-conceptuales y metodológicos de la investigación, incluyendo, en forma sucinta, las argumentaciones principales del pensamiento de Dabène respecto a las fases de politización de los procesos de integración. Posteriormente, se realiza el análisis en tres etapas de las dinámicas en torno a los esquemas de ALBA, UNASUR y MERCOSUR.

Se considera que este artículo puede aportar, aunque modestamente, a la literatura sobre regionalismo en América Latina, en general, y en Sudamérica, en particular, al aplicar el marco teórico-conceptual de ciclos de politización de Dabène a un fenómeno reciente, cual es la pérdida de dinamismo de los esquemas de cooperación e integración instituidos o reformados bajo las premisas del regionalismo postliberal.

\section{Lineamientos teórico-conceptuales $\mathbf{y}$ metodológicos}

Evitando conceptualizaciones sustentadas en la experiencia europea, Dabène brinda una definición de politización de los procesos de integración regional que se centra en la voluntad de los actores en alcanzar una meta política colectiva (por ejemplo, la resolución de crisis o la consolidación de la democracia), a través de la integración económica, y argumenta que el grado de politización constituye un valioso factor para determinar la vitalidad de esos procesos o su ausencia (Dabène, 2012).

Su hipótesis principal para el caso latinoamericano es que la manera en la cual se concatenan las secuencias y el nivel de politización en un proceso de integra-

5 La elección de estos tres esquemas se relaciona con el hecho de que "las transformaciones en la cooperación subregional con la formación de la UNASUR, los cambios en el Mercosur, con su mayor énfasis en la dimensión política [...] así como la constitución de la ALBA, bajo liderazgo venezolano" condujeron a "lo que la literatura denominó regionalismo posliberal" (Soares de Lima, 2016, p. 86). 
ción permite explicar su resiliencia, a pesar de las crisis repetidas y de sus resultados limitados (Dabène, 2012; Dubé, 2015). ${ }^{6}$ El autor modifica ligeramente su teorización en el tiempo y mientras en su obra más antigua el énfasis está colocado en el compromiso por parte de los principales actores políticos por compartir intereses comunes, el nivel de institucionalización y el rango de temas factibles de ser discutidos en el ámbito regional (Dabène, 2009, p. 30, cursivas de la autora), en su obra más reciente, la construcción de intereses comunes y la de instituciones regionales siguen siendo dimensiones importantes, pero la tercera dimensión está constituida por la participación de actores no-estatales (Dabène, 2012, p. 42).

Se puede, así, abordar la "operacionalización” de los conceptos presentes en la argumentación de Dabène sobre politización $\mathrm{y}$, de tal manera, es posible deducir unos indicadores que faciliten la contrastación empírica del concepto por analizar (Cea D’Ancona, 1996, p. 123). En un ejercicio de sobresimplificación, se utilizan dos elementos comunes en sus teorizaciones - la construcción de intereses comunes y la de instituciones regionales-, esenciales (aunque no exclusivos) para analizar el paso de una fase de politización a otra.

Cabe aclarar que la agenda de investigación de Dabène generó trabajos diversos; por ejemplo, el de Ribeiro Hoffmann (2015), que explora el vínculo entre politización y legitimidad en el MERCOSUR, identificando "picos" de politización en años recientes y los principales actores que promovieron dicha politización. Por su parte, Dubé (2015) retoma la explicación de Dabène sobre la resiliencia del regionalismo en América Latina, para contraponer una diferente, basada en el cálculo costos-beneficios; mientras que Rivarola Puntigliano y Briceño Ruiz (2013) intentan resolver el "misterio Dabène" (Dabène, 2009, p. 5), explicando la resiliencia de los proyectos de integración por tres factores (desarrollo socioeconómico, autonomía regional e identidad común). Otro ejemplo es el trabajo de Quiliconi y Rivera (2019), quienes conectan la definición de politización de Dabène con el concepto de ideología, para analizar de qué manera la convergencia/divergencia ideológica de los ejecutivos nacionales repercute en la cooperación regional sudamericana.

6 El nivel de politización alcanzado durante la secuencia 1 (politización) es suficiente para prevenir el colapso del proceso durante la secuencia 2 (despolitización), porque hay cierta consistencia en el compromiso de los actores o porque las instituciones proporcionan un mínimo de resiliencia. La secuencia 3 (repolitización) implica la construcción de un nuevo proyecto y una renovada concepción de intereses en común en el nivel regional, e incluso nuevas metas políticas luego de una crisis. Esta secuencia no necesariamente es lineal ni progresiva; tampoco existe una variable independiente que explique, de manera exclusiva, el paso de una fase a la otra (Dabène, 2012, p. 44). 
La estrategia de investigación de este trabajo es el estudio de casos, en especial, el de aquellos múltiples (Cea D’Ancona, 1996), con foco en ALBA, UNASUR y MERCOSUR, a través de estrategias cualitativas de recogida de información (revisión de fuentes de observación secundaria mediante bibliografía y documentos) y el uso de la técnica documental de análisis de datos (Cea D'Ancona, 1996, pp. 88-89).

\section{La etapa de (re)politización: el regionalismo postliberal}

En los primeros años del siglo XXI, se evidenció una renovación política en Sudamérica, donde gobiernos de izquierda recuperaron el espacio político para redefinir prioridades en relación con la distribución de ingresos y el rol del Estado. Tanto los intereses, la racionalidad y los objetivos de la integración regional como las estrategias internacionales de inserción y las políticas de desarrollo fueron puestos en debate (Sanahuja, 2012).

De esta manera, se dio el contexto propicio para el advenimiento de una nueva ola de regionalismo, caracterizada por la aparición de estructuras que se superpusieron a esquemas preexistentes. El ciclo de politización se manifestaba en nuevas y enriquecidas agendas, que iban más allá de las cuestiones centradas en el comercio, agregando compromisos gubernamentales en pos de profundizar la integración en una "secuencia repolitizada post-comercial del regionalismo" (Dabène, 2012, pp. 42 y 61). ${ }^{7}$

A pesar de que existen diferencias entre ALBA y UNASUR, en términos generales, estos esquemas se caracterizan por la convergencia de temas y áreas de acción en torno a un "retorno de la agenda de desarrollo", "retorno de la política" y "retorno del Estado" (Serbin, 2012, p. 79). La ola de regionalismo postliberal fue una opción más política que económica para los países sudamericanos y, en todo caso, claramente no eliminó la opción clásica de libre comercio (Dabène, 2014, p. 70), como se reflejó con la conformación de la Alianza del Pacífico.

7 El autor, sin embargo, desconfiaba de las contribuciones efectivas de UNASUR o ALBA, si se tenía en cuenta la larga historia de secuencias de politización seguidas de despolitización que se produjeron en la trayectoria del regionalismo latinoamericano (Dabène, 2012, p. 63). 


\subsection{ALBA}

Conformada en el 2004, a partir de una alianza entre la Venezuela de Hugo Chávez y la Cuba de Fidel Castro, como un esquema de asistencia y de cooperación sur-sur, el ALBA presenta un fuerte contenido ideológico antiestadounidense (Briceño Ruiz, 2014), que, con la inclusión del programa Petrocaribe, ${ }^{8}$ reforzaba el contrapunto con el regionalismo abierto. Fue sumando gobiernos estrechamente aliados a Chávez, como Bolivia, Nicaragua y Dominica; posteriormente, Ecuador y algunos países del Caribe. ${ }^{9}$

El ALBA representa un intento sin precedentes en el regionalismo latinoamericano por promover una agenda no basada exclusivamente en la liberalización comercial, sino en la cooperación interestatal, el intercambio de recursos humanos y la solidaridad (Riggirozzi, 2012, p. 140). En efecto, encarna un proyecto radical de transformación ideológica para extender el socialismo del siglo XXI a un esquema de cooperación regional directamente opuesto al neoliberalismo.

El bloque se dotó de una estructura institucional laxa, fundamentada en órganos intergubernamentales: consejos, comités y grupos de trabajo, incluyendo, como novedad, un Consejo de Movimientos Sociales. ${ }^{10}$ Sin embargo, hacia 2012, en pleno auge del ALBA, ya existían dudas sobre su capacidad para construir los consensos en torno a intereses comunes que requería un proyecto viable. En todos los Estados miembros menos en Cuba, el ALBA era sólo una de las diversas formas de integración regional que se perseguían en paralelo, y no necesariamente la que se priorizaba (Cusack, 2019, p. 107). ${ }^{11}$

8 Petrocaribe es un mecanismo mediante el cual Venezuela vende petróleo en condiciones especiales a sus vecinos de la Cuenca del Caribe y Centroamérica (Briceño Ruiz, 2014, p. 169).

9 Adhesiones al ALBA: Bolivia (2006); Nicaragua (2007); Dominica y Honduras (2008); Antigua y Barbuda, Ecuador, San Vicente y las Granadinas (2009); Santa Lucía (2013); San Cristóbal y Nieves y Granada (2014) (SELA, 2015). Honduras se retiró del bloque en el 2010, mientras que Ecuador lo hizo en el 2018.

10 El ALBA-TCP se estructura a partir del Consejo Presidencial, los consejos ministeriales político, económico y social, más un Consejo de Movimientos Sociales. Asimismo, cuenta con un Comité de la mujer e igualdad de oportunidades, una Comisión Política, un Comité de Defensa de la Naturaleza y una Secretaría Ejecutiva, entre otros órganos (MRE, 2009).

11 Algunos integrantes del ALBA son, al mismo tiempo, parte de UNASUR, MERCOSUR, la CAN o la Comunidad del Caribe (CARICOM). 


\subsection{UNASUR}

Desde el 2008, UNASUR constituye una construcción regional diseñada por Brasil, a partir de la anterior iniciativa de la Comunidad Sudamericana de Naciones, que se edificó sobre la base de intereses comunes en establecer una estructura institucional sudamericana en temas más allá del comercio, mientras buscaba, al mismo tiempo, una posición autónoma en relación con actores extraregionales.

La creación e institucionalización de UNASUR pueden ser explicadas por la convergencia ideológica entre los gobiernos de los Estados participantes, de tinte progresista (Quiliconi y Rivera, 2019). Si bien los Estados miembros se decantaron por una institucionalización ligera, el Tratado Constitutivo preveía la creación de consejos ministeriales sectoriales y un parlamento, que se regularía mediante un protocolo adicional a dicho Tratado.

Las contribuciones de UNASUR incluyeron la construcción de un espacio eficaz para la solución de conflictos presentados en la región, ${ }^{12}$ la creación del Consejo Suramericano de Defensa, en el cual se discutieron temas tradicionalmente sensibles para los Estados sudamericanos, y, más aún, la delineación de un espacio institucional que logró ofrecer una variedad de políticas públicas a la región, ${ }^{13}$ gracias a la actuación de los consejos sudamericanos, a través de redes intergubernamentales, independientemente de los ciclos y procesos políticos (Hoffmann, 2019).

\subsection{MERCOSUR}

A partir del 2003, con la firma del Consenso de Buenos Aires por los entonces presidentes de Argentina y Brasil (Néstor Kirchner y Lula da Silva), el MERCOSUR intentó renovarse, al introducir una serie de cambios para complementar la dimensión comercial del bloque con políticas en los ámbitos sociales y

12 Entre ellos, se puede mencionar la crisis política en Bolivia, en el 2008, por las iniciativas separatistas de las provincias de la Media Luna; el golpe de Estado contra el presidente Zelaya en Honduras en junio de 2009, o el intento de golpe de Estado en Ecuador en septiembre de 2010.

13 Se destaca la cooperación en materia de infraestructura, a través del Consejo de Infraestructura y Planeamiento (COSIPLAN), que absorbió los proyectos desarrollados en la Iniciativa para la Infraestructura Regional Suramericana (IIRSA). También se crearon consejos para discutir temas de energía, salud, desarrollo social, finanzas, cultura, educación, ciencia, tecnología e innovación, entre otros (portal UNASUR www.unasursg.org) 
productivos. La visión común de los presidentes contribuyó a la generación de consensos en torno a ciertos intereses comunes, que podían ser alcanzados en un marco subregional renovado.

En términos prácticos, la financiación de proyectos con el Fondo de Convergencia Estructural del MERCOSUR (FOCEM), así como las iniciativas institucionales del MERCOSUR Social, para los derechos laborales, y la creación del Tribunal Permanente de Revisión fueron elementos de politización que marcaron ciertas transformaciones en el contexto de las formas de regionalismo postliberales.

En concordancia con la etapa de un nuevo regionalismo, comenzó a tener mayor preeminencia no solo la dimensión social, sino también la ciudadana (Porcelli, 2013, p. 3). Avanzando en este sentido, en diciembre de 2005, los países miembros aprobaron la constitución de un parlamento para el bloque, que entró en pleno funcionamiento en mayo de 2007.

La novedad principal de ese parlamento residía en el hecho de que sus integrantes debían ser elegidos en forma directa por la ciudadanía, lo que lo convertía en la única institución con representación democrática. ${ }^{14}$ Más allá de que algunos países elegían a los parlamentarios y el resto enviaba delegados de sus congresos nacionales, la elección directa constituía una señal clara en favor de la politización del bloque. Mallmann y Dri, en esta línea, argumentan que con la creación del Parlamento del MERCOSUR, el proceso de integración alcanzó "su nivel más elevado de politización" (2011, p. 221).

En este periodo de politización, Venezuela fue admitida, aprovechando la suspensión de Paraguay. El tratado de incorporación de Venezuela al bloque se firmó en el 2006, pero la ratificación dependía de los congresos nacionales y estuvo bloqueada por el senado paraguayo hasta el 2013. Venezuela fue finalmente admitida cuando, a su vez, Paraguay fue suspendido, debido al juicio político que llevó a la destitución del presidente Fernando Lugo (Ribeiro Hoffmann, 2015, p. 65; Van Klaveren, 2018, p. 68).

14 El único país que cumplió con el plazo fue Paraguay, el cual eligió a sus representantes en las elecciones de 2008 y luego en el 2013. Lo siguió Argentina, en el 2015. 


\section{La etapa de despolitización: el declive del regionalismo postliberal}

América Latina (y Sudamérica) cuentan con una extensa trayectoria de etapas de politización continuadas de fases de despolitización. Una década después del surgimiento de esquemas subregionales de cooperación e integración con tono progresista, como ALBA y UNASUR, desde los últimos años, se asiste a fuertes movimientos en detrimento de su dinamismo y supervivencia. Especialmente, una nueva concepción de intereses comunes suscitada en los gobiernos conservadores de varios países sudamericanos y una débil institucionalización predispusieron a la creciente fragilidad de los esquemas postliberales.

\subsection{ALBA}

Hace unos años, Serbin sostenía que el ALBA califica para ser identificado "con un regionalismo que aspira a ser post-hegemónico y que se presenta como post-liberal" solo si logra "una institucionalidad más estructurada y una sostenibilidad independiente de los precios internacionales del petróleo y de los avatares de la política doméstica en Venezuela" (Serbin, 2012, p. 107).

Los hechos han confirmado que ALBA no logró ser independiente de esos factores - porque en realidad nunca fue preparada para serlo- $y$, consecuentemente, con el descalabro político, económico y social de Venezuela, más un descenso abrupto en la renta petrolera de ese país, el esquema se debilitó. Manifiestamente, la sostenibilidad y la solidaridad no se garantizan, si dependen de la renta petrolera o de cualquier otro producto. A falta de incentivos económicos, un mayor involucramiento en los propósitos generales del proyecto se dificulta.

En el plano institucional, la sobreabundancia de propuestas poco viables, los recursos humanos limitados e inestables, la existencia de múltiples órganos con responsabilidades escasamente claras, la supervisión infrecuente e irregular, la débil rendición de cuentas y la limitada planificación resultaron en una combinación negativa que llevó a que las iniciativas de ALBA comenzaran a fallar (Cusack, 2019, pp. 38-39).

Inclusive, aunque ALBA aparecía como un esquema natural y esencialmente proclive a abrazar los planteamientos de los movimientos sociales, "en la práctica no deja de ser [...] básicamente una iniciativa inter-estatal y, más pre- 
cisamente, inter-presidencial, de cooperación donde persisten las mismas limitaciones y un similar déficit democrático señalado para otros procesos de integración" (Serbin, 2012, p. 104). El Consejo de Movimientos Sociales, por ejemplo, no posee poder real en la toma de decisiones del bloque (Serbin, 2012, p. 103; Cusack, 2019, p. 39).

Desde el 2012, el ALBA muestra una agenda menos activa y, especialmente desde la muerte de Chávez en marzo de 2013, no se vislumbra una coincidencia evidente en torno a los intereses comunes que organizaron al esquema. A su vez, fue perdiendo integrantes: el gobierno ecuatoriano anunció su retiro del ALBA como consecuencia de la crisis migratoria. ${ }^{15}$

En la actualidad, los arreglos institucionales y los intereses comunes se mantienen de manera frágil: las reuniones de algunos de sus consejos y la celebración de encuentros cumbres entre Venezuela y sus viejos aliados ideológicos, como Cuba, Bolivia, Nicaragua y El Salvador, no logran disimular cierto retroceso del bloque en términos concretos de integración y cooperación, que intentan ser compensadas con una retórica antiestadounidense cada vez más exaltada.

\subsection{UNASUR}

El bloque fue perdiendo fuelle gradualmente. A medida que el signo político de las presidencias de los países sudamericanos fue girando a la derecha, lo hicieron también sus intereses en política exterior. UNASUR dejó de ser importante y, para muchos, se transformó en una forma de mantener el legado de una izquierda que había sido derrotada en las urnas y, en el caso de Venezuela, había iniciado un camino de ruina.

Se comenzó un claro proceso de despolitización, especialmente en términos institucionales, a partir de enero de 2017, cuando la organización quedó acéfala y su funcionamiento prácticamente se redujo a lo elemental, al menos en contraste con el protagonismo político que tuvo desde su fundación hasta finales de 2016.

15 No sólo se retiró Ecuador de ALBA en el 2018. De Petrocaribe, se retiró Guatemala en el 2014 y Belice en el 2017. En junio de 2018, Venezuela anunció la suspensión de sus envíos a Antigua y Barbuda, Dominica, El Salvador, Nicaragua, San Vicente y las Granadinas, San Cristóbal y Nieves y Haití (Antonin, 2018). 
Incluso el Parlamento de UNASUR nunca se creó. Paradójicamente, sin contar siquiera con un instrumento jurídico de creación, se construyó el edificio que albergaría su sede. ${ }^{16} \mathrm{El}$ establecimiento de este parlamento regional parecía más un negocio para las empresas constructoras y el gobierno boliviano que un paso hacia la democratización del proceso (Alvarez, 2017).

En abril de 2018, los gobiernos de Argentina, Brasil, Chile, Colombia, Paraguay y Perú tomaron la decisión de suspender temporalmente su membresía, hasta que no se garantizase "el funcionamiento adecuado de la organización" (France24, 2019). Posteriormente, a lo largo del 2019, esos mismos gobiernos, junto con el de Ecuador, formalizaron su salida del bloque. Inclusive Ecuador desalojó a UNASUR de su sede en Quito. Con estas desvinculaciones, los únicos integrantes de UNASUR que siguen activos son Uruguay, Guyana, Bolivia, Surinam y Venezuela.

Hoy, el colapso de la UNASUR, impensable hace diez años en muchos círculos que promovieron la institucionalización de este organismo, parece inevitable. Sin embargo, y mientras siga presente una mayoría de gobiernos liberales-conservadores, la desaparición de UNASUR intenta ser disimulada con la creación de la iniciativa denominada Foro para el Progreso de América del Sur (Prosur).

\subsection{MERCOSUR}

Una vez que terminaron sus mandatos, los gobiernos de izquierda de los países miembros, y fallecido Chávez, el presidente Maduro no pudo evitar la suspensión de Venezuela del MERCOSUR por tiempo indefinido, con el argumento de que el orden democrático en ese país se había interrumpido.

La despolitización se evidencia, además, en la decisión de abril de 2019, adoptada por Paraguay y secundada por Argentina y Brasil, de suspender la elección de los parlamentarios a través de sufragio directo y universal. El Parlamento funcionará, entonces, integrado por legisladores provenientes de los congresos nacionales, como lo hizo en sus orígenes.

Las elecciones directas de los parlamentarios regionales formaron parte de las reformas de (re)politización del bloque en clave postliberal y se percibían como un medio para la promoción de la participación ciudadana en el proceso de inte-

16 El edificio demandó una inversión de 61700000 dólares. Evo Morales, al inaugurarlo, lo ofreció para actos escolares, asambleas sindicales y bodas (El Universo, 2018). 
gración, el aumento de la legitimidad democrática y la (eventual) construcción de una ciudadanía e identidad mercosureñas (Alvarez, 2017). El abandono del sistema de elección directa denota la voluntad explícita de los Estados parte por despolitizar el proyecto.

La impronta que dieron a MERCOSUR los gobiernos de izquierda durante la década pasada se veía como un lastre al desarrollo económico por parte de los gobiernos que accedieron al poder en Brasil y Argentina, a partir de 2015. Consecuentemente, con este argumento, los gobiernos de Bolsonaro y Macri deseaban "actualizar" al MERCOSUR, es decir, disminuir sus costos y flexibilizar sus reglas.

\section{La etapa de repolitización?: el futuro del regionalismo postliberal}

Luego de una secuencia de despolitización, es posible que el regionalismo logre ser resiliente, a partir del establecimiento de nuevos objetivos, siempre que sea coherente con una representación de intereses comunes (Dabène, 2012, pp. 60-61). Ante una arquitectura regional "compleja, a ratos contradictoria y hasta caótica" (Van Klaveren, 2018, p. 71), surgieron iniciativas y esfuerzos para "renovar" los esquemas postliberales. En sustitución de UNASUR, emergió Prosur, de la mano de gobiernos conservadores, en un intento por construir una gobernanza regional más "pragmática", "desideologizada" y “eficaz" (Sanahuja, 2019, p. 115). El MERCOSUR, mientras tanto, recuperó vitalidad y actualidad, al alcanzar ciertos logros (más simbólicos que tangibles) en su agenda comercial externa. ALBA, por su parte, se debate entre la inercia y el ocaso prematuro.

\subsection{ALBA}

Las severas limitaciones de la "diplomacia petrolera" de Venezuela, la pérdida de integrantes y las deficiencias institucionales atentan contra cualquier intento de profundización o repolitización del bloque. El ALBA consigue, sin embargo, cierto grado de resiliencia más debido a la obstinación de Maduro y a algunos resultados positivos en términos sociales (obtenidos en los primeros años) que al desempeño de las instituciones del bloque o la coincidencia de intereses. 
Es dudoso que este esquema tome el camino de la repolitización; probablemente, se debata entre dos opciones: mantenerse en estado inercial o iniciar un lento proceso de desaparición. En todo caso,

el ALBA dista mucho de haberse consolidado y, probablemente, como propuesta radical, la alianza está destinada a un ocaso prematuro pero exitoso, ya que en el corto plazo casi todos los actores han conseguido los objetivos mínimos que impulsaron su adhesión (Benzi, 2016, p. 90).

\subsection{Prosur}

El 22 de marzo de 2019, ocho países sudamericanos crearon el Prosur. ${ }^{17}$ Tal como ha sido mencionado, la implementación de un nuevo esquema regional puede considerarse una fase de (re)politización desde la perspectiva de Dabène, en la cual aparecen nuevos objetivos políticos luego de una crisis (Dabène, 2012, p. 47). Sin embargo, en el caso de Prosur, la crisis fue autoinfligida, en el sentido de que estaba vinculada al "vaciamiento" de UNASUR, a partir de la desvinculación de la mayoría de sus integrantes. El Prosur, entonces, se erige en torno a intereses comunes en pos de objetivos políticos concretos de los gobiernos de derecha: aislar a Venezuela y hacer desaparecer la UNASUR.

En términos institucionales, se visualiza la voluntad unívoca de los jefes de Estado de evitar estructuras burocráticas, lentas y rígidas. En este sentido, la Declaración de Santiago enuncia que el Prosur deberá "tener una estructura flexible, liviana, no costosa, con reglas de funcionamiento claras y con un mecanismo ágil de toma de decisiones [...]” (Casa Rosada, 2019).

La creación de Prosur, un esquema supuestamente "desideologizado", está, contrariamente, repleto de razones ideológicas. Los gobiernos firmantes de la Declaración de Santiago comparten el interés de sustituir el gobierno de Maduro - por otro de diferente signo político — y la UNASUR, organismo paradigmático de los gobiernos progresistas de Lula, Kirchner y Chávez. Más allá de estas metas, no queda claro qué tipo de cooperación o integración se quiere llevar adelante. 


\subsection{MERCOSUR}

Pese a los llamados a la flexibilización de las reglas del bloque para que los Estados parte puedan acordar con terceros países, la firma de un acuerdo preliminar en el ámbito comercial, con miras a la creación de una Asociación Birregional con la Unión Europea en junio de 2019, hizo resurgir intereses y objetivos comunes, lejos de la agenda política postliberal, más bien, en torno a la agenda comercial.

La firma del acuerdo, a su vez, impulsó el cierre de las negociaciones con la Asociación Europea de Libre Comercio. ${ }^{18}$ Tal como enunciaba el comunicado conjunto, el cierre de esta negociación "...sumada a la reciente conclusión de la negociación con la UE, es una nueva muestra de los logros que el MERCOSUR puede obtener cuando sus Estados Partes trabajan con coincidencia de objetivos" (MREC, 2019).

El MERCOSUR mantiene negociaciones para alcanzar acuerdos comerciales también con Canadá, Singapur y la República de Corea. En este sentido, el bloque se estaría (re)politizando parcialmente, a través de la concordancia de intereses en torno a la apertura de mercados y la promoción de negocios e inversiones, mientras que su estructura institucional persiste en la inercia, con signos preocupantes para la democratización del proceso.

\section{Reflexiones finales}

El objetivo del trabajo ha sido analizar si ALBA, UNASUR y MERCOSUR se encuentran en una fase de despolitización y posible (re)politización, teniendo en cuenta, simplificadamente, dos elementos que se derivan del esquema teóricoconceptual de Dabène: la concepción de intereses comunes y la construcción de arreglos institucionales. Siguiendo esta lógica, se considera que en los últimos años los esquemas regionales en Sudamérica se despolitizaron y, posteriormente, (re)politizaron, condenando y negando el regionalismo postliberal: la herencia "ideologizada" de los gobiernos populares.

Obviamente, el énfasis en los intereses comunes y los arreglos institucionales no significa que otros elementos no sean parte de la explicación. Claramente, se

18 Bloque integrado por Islandia, Liechtenstein, Noruega y Suiza. 
abre una interesante agenda de investigación a futuro, en especial, si se complementa con variables externas como el vínculo de la región con Estados Unidos, el impacto del sistema internacional en los órdenes domésticos o el papel de los liderazgos regionales, entre otras.

Si el grado de politización constituye un valioso factor para determinar la vitalidad del regionalismo o su ausencia, entonces, UNASUR y ALBA se encuentran en una fase de debilidad. Para el MERCOSUR, no obstante, el panorama es mixto. En efecto, la UNASUR se desintegra y una nueva fase de "repolitización" pretende su sustitución a través del Prosur, como resultado del rechazo a los esquemas basados en la agenda política y en la convergencia ideológica progresista, aunque en realidad la convergencia ahora exista, solo que con signo opuesto (Sanahuja, 2019, p. 122).

En este ciclo político, el ALBA encuentra sus propios límites internos y no logra erigirse como "otra integración posible" o como una "integración alternativa". Probablemente, se mantenga en un estado inercial o, antes de haberse consolidado, ya esté iniciando su final. Por su parte, el MERCOSUR heredado de los gobiernos de izquierda, considerado un anacronismo, toma nuevo impulso con la convergencia de intereses comunes, esta vez, en torno a una remozada agenda comercial externa, mientras retrocede en el grado de institucionalidad democrática alcanzada.

Sin embargo, se debe tener en cuenta que estas instancias, especialmente ALBA y UNASUR, están paralizadas, pero no disueltas. Podrían reactivarse, si las circunstancias políticas lo permiten (Sanahuja, 2019, p. 145). La probable reelección de Evo Morales en Bolivia, el posible triunfo de la centro-izquierda en Argentina y Uruguay, así como la presencia de López Obrador en México facilitarían "recrear un polo progresista en América Latina como primer paso para regenerar la integración regional" (Sued, 2019). De esa manera, se habilitaría la posibilidad de hablar simplemente de un "paréntesis" en la región (Racovschik y Raimundi 2016), en un conocido ciclo cambiante de proyectos regionales, nuevamente dependiente del signo ideológico de los líderes regionales. 


\section{Referencias}

Alvarez, M. V. (2017). La representación política en espacios transnacionales: una comparación de los parlamentos regionales en América Latina. Cuadernos del CIESAL, 14(16), 49-76.

Antonin, A. (2018). ¿Dónde está el dinero de Petrocaribe? Las protestas anticorrupción que acorralan al gobierno haitiano. Recuperado de https://nuso.org/ articulo/haiti-corrupcion-petrocaribe-venezuela/

Benzi, D. (2016). El exitoso ocaso del ALBA. Réquiem para el último vals tercermundista. Nueva Sociedad, 261, 77-91.

Bizzozero, L. (2011). Aportes del MERCOSUR al regionalismo y a la teoría política de la integración regional. Una mirada desde los veinte años del proceso, Boletim Meridiano 47, 12(125), 4-10.

Briceño Ruiz, J. (2011). Del regionalismo estratégico al regionalismo social y productivo. Las transformaciones del modelo de integración en el MERCOSUR, en J. Briceño Ruiz (ed.), El MERCOSUR y las complejidades de la integración regional (pp. 121-162). Buenos Aires: TESEO.

Briceño-Ruiz, J. (2014). El ALBA: una discusión de su modelo, sus resultados y sus perspectivas. En A. Serbin, L. Martínez y H. Ramanzini Júnior (coords.), Anuario de la Integración Regional de América Latina y el Caribe (pp. 151178). Buenos Aires: CRIES.

Casa Rosada. (2019). Declaración Presidencial sobre la Renovación y Fortalecimiento de la Integración de América del Sur. Recuperado de https://www. casarosada.gob.ar/informacion/actividad-oficial/9-noticias/45052-declaracion-presidencial-sobre-la-renovacion-y-fortalecimiento-de-la-integracionde-america-del-sur

Cea D’ancona, M. A. (1996). Metodología cuantitativa: estrategias y técnicas de investigación social. Madrid: Editorial Síntesis.

Cusack, A. K. (2019). Venezuela, ALBA, and the Limits of Post-neoliberal Regionalism in Latin America and the Caribbean. Nueva York: Palgrave Macmillan.

Dabène, O. (2009). The Politics of Regional Integration in Latin America: Theoretical and Comparative Explorations. Nueva York: Palgrave Macmillan.

Dabène, O. (2012). Consistency and Resilience through Cycles of Repoliticization. En P. Riggirozzi Y D. Tussie (eds.), The Rise of Post-hegemonic Regionalism. The Case of Latin America (pp. 41-64). Londres: Springer.

Dabène, O. (2014). La quatrième vague de régionalisme. En S. Quenan, C. y S. Velut (eds.), Les enjeux du développement en Amérique latine. Dynamiques 
socioéconomiques et politiques publiques (pp. 64-95), Deuxième édition. París: Institut des Amériques.

Da Motta, P. y Ríos, S. (2007). O Regionalismo pós-liberal na América do Sul: origens, iniciativas e dilemas. Serie Comercio Internacional, 62. Santiago de Chile: CEPAL.

Dubé, S. (2015). Lo racional es invisible a los ojos: cálculos estratégicos y resiliencia de la agenda integracionista latinoamericana. Ponencia presentada en el Congreso de la Asociación Latinoamericana de Ciencia Política - ALACIP, Lima.

France24. (22 de abril de 2018). Seis países suramericanos anunciaron suspender su participación en UNASUR. Recuperado de https:/www.france24.com/ es/20180421-unasur-paises-miembros-retiran-bloque

El Universo. (20 de septiembre de 2018). Flamante y costoso edificio del Parlamento de UNASUR en Bolivia, sin uso. Recuperado de https://www.eluniverso. com/noticias/2018/09/20/nota/6962429/flamante-costoso-edificio-parlamento-unasur-bolivia-queda-uso

Hoffmann, A. M. (2019). Regional Governance and Policy-Making in South America. Cham: Palgrave Macmillan.

Hurrell, A. (1995). Regionalism in Theoretical Perspective. En L. Fawcett y A. Hurrell (eds.), Regionalism in World Politics: Regional Organization and International Order (pp. 37-73). Nueva York: Oxford University Press.

Malamud, A. y Gardini, G. L. (2012). Has regionalism peaked? The Latin American Quagmire and its Lessons. The International Spectator: Italian Journal of International Affairs, 47(1), 116-33.

Mallmann, M. I. y Dri, C. (2011). Institucionalización y politización de la integración. En J. Briceño Ruiz (ed.), El MERCOSUR y las complejidades de la integración regional (pp. 203-223). Buenos Aires: TESEO.

Ministerio de Relaciones Exteriores de Bolivia. (2009). ALBA-TCP El Amanecer de los Pueblos. La Alianza Antiimperialista de los Pueblos de Nuestra América. Recuperado de http:/www.cancilleria.gob.bo/webmre/sites/default/files/ libros/Alba-tcp $\% 20$ el\%20amanecer\%20de\%20los\%20pueblos.pdf

Ministerio de Relaciones Exteriores y Culto de Argentina. (2019). Comunicado conjunto: cierre de las negociaciones Mercosur EFTA. Información para la Prensa $N^{\circ}$ : 334/19. Recuperado de https://www.cancilleria.gob.ar/es/actualidad/noticias/comunicado-conjunto-cierre-de-las-negociaciones-mercosurefta 
Porcelli, E. (2013). Parlamento del MERCOSUR: un proceso de instalación en distintas velocidades. Ponencia presentada en el VI Encuentro del CeRPI y IV Jornada del Censud, Democracia y Relaciones Internacionales en América Latina.

Quiliconi, C. y Rivera, R. (2019). Ideología y liderazgo en la cooperación regional: los casos del Consejo Suramericano de Defensa y el Consejo Suramericano sobre el Problema Mundial de las Drogas en UNASUR. Revista Uruguaya de Ciencia Politica, 28(1), 219-248.

Racovschik, M. A. y Raimundi, C. (2016). ¿Fin de ciclo o paréntesis en la región? Balance de la última década y reflexiones sobre el nuevo escenario para el MERCOSUR. Documento de Trabajo no. 4. Buenos Aires: FLACSO Argentina.

Ribeiro-Hoffmann, A. (2015). Politicization and Legitimacy in MERCOSUR. En A. Hurrelmann y S. Schneider, The Legitimacy of Regional Integration in Europe and the Americas (pp. 57-72). Basingstoke: Palgrave Macmillan.

Riggirozzi, P. (2012). Re-territorializando consensos: Hacia un regionalismo posthegemónico en América Latina. En A. Serbin, L. Martínez y H. Ramanzini Júnior (coord.), Anuario de la Integración Regional de América Latina y el Gran Caribe (pp. 129-151). Buenos Aires: CRIES.

Riggirozzi, P. y Tussie, D. (eds.). (2012). The Rise of Post-hegemonic Regionalism. The Case of Latin America. Londres: Springer.

Rivarola-Puntigliano, A. y Briceño-Ruiz, J. (2013). Resilience of Regionalism in Latin America and the Caribbean. Nueva York: Palgrave Macmillan.

Sanahuja, J. A. (2010). La construcción de una región: Suramérica y el regionalismo posliberal. En M. Cienfuegos y J. A. Sanahuja (coord.), Una región en construcción. UNASUR y la Integración de América del Sur (pp. 87-134), Barcelona: CIDOB.

Sanahuja, J. A. (2012). Regionalismo post-liberal y multilateralismo en Sudamérica: El caso de UNASUR. En A. Serbin, L. Martínez y H. Ramanzini Júnior (coord.), Anuario de la Integración Regional de América Latina y el Gran Caribe (pp. 19-71). Buenos Aires: CRIES.

Sanahuja, J. A. (2016). Regionalismo e integración en América Latina: de la fractura Atlántico-Pacífico a los retos de una globalización en crisis. Pensamiento Propio, 44 (21), 29-75.

Sanahuja, J. A. (2019). La crisis de integración y el regionalismo en América Latina: giro liberal-conservador y contestación normativa. En M. Mesa (coord.), Ascenso del nacionalismo y el autoritarismo en el sistema internacional Anuario 2018-2019 (pp. 107-126). Madrid: CEIPAZ. 
SELA. (n. d.). ¿Qué es la CELAC? Recuperado de http://www.sela.org/celac/quienes-somos/que-es-la-celac/

Serbin, A. (2012). Déficit democrático y participación ciudadana en el marco del regionalismo post-liberal. En A. Serbin, L. Martínez y H. Ramanzini Júnior (coord.), Anuario de la Integración Regional de América Latina y el Gran Caribe (pp. 73-127). Buenos Aires: CRIES.

Soares De Lima, M. R. (2016). Heterogeneidad en Sudamérica y el papel de Brasil. En B. Ayllón (ed.), ¿Latinoamérica dividida? Procesos de integración y cooperación Sur-Sur (pp. 75-97). Quito: Editorial IAEN.

Sued, G. (2019, 16 de septiembre). Alberto Fernández imagina una reedición de la UNASUR con gobiernos progresistas de la región, La Nación. Recuperado de https://www.lanacion.com.ar/politica/el-candidato-imagina-una-reedicion-de-la-unasur-con-gobiernos-progresistas-de-la-region-nid2288114

Van Klaveren, A. (2012). América Latina en un nuevo mundo. Revista CIDOB d'Afers Internacionals, 100, 131-150.

Van Klaveren, A. (2018). El eterno retorno del regionalismo latinoamericano. Nueva Sociedad, 275, 62-72.

Vivares, E. y Dolcetti-Marcolini, M. (2016). Dos regionalismos, dos Latinoaméricas o después de Latinoamérica. En B. Ayllón (ed.), ¿Latinoamérica dividida? Procesos de integración y cooperación Sur-Sur (pp. 23-49). Quito: Editorial IAEN. 